ARTIGO

\title{
Desbravamento, agricultura e doença: a doença de Chagas no Estado de São Paulo
}

** Faculdade de Ciências Médicas da UNICAMP, Campinas-SP.

\begin{abstract}
* Este artigo é sintese de tese de doutoramento apresentada d̀ $\mathrm{Fa}$. culdade de Medicina de Ribeirão Preto da USP em 1981. Apresentado no Encontro do Grupo de Trabalho sobre Geografia da Saude da União Geográfica Internacional. Brasitia, DF, 11 a 14 de agosto de 1982.
\end{abstract}

\author{
Luiz Jacintho da Silva *
}

Faz-se uma reconstrução do processo de surgimento, disseminação e desaparecimento da endemia chagásica no Estado de São Paulo, interpretando-se as informaçōes epidemiológicas existentes, dentro de uma perspectiva histórico-materialista. Parte-se dos conceitos clássicos que procuram explicar a distribuição da doença, demonstrando sua insuficiência. Com a incorporação de conceitos e métodos de análise utilizados em Geografia, chega-se a uma compreensão do que foi o processo de evolução da doença em São Paulo, e quais os seus determinantes, mostrando que se tratou de um processo peculiar ao Centro-Sul brasileiro, num periodo histórico bem determinado.

$A$ doença de Chagas, ainda que uma endemia de expressão nacional, não pode ser vista como um todo indistinto, existindo diferentes padrões epidemiológicos em periodos históricos diferentes.

||||||||||||||||||||||||||||||||||||||||||||||||||||||||||||||||||||||||||||||||||||||||||||||||||||||||||

\section{INTRODUÇÃO}

As doenças, tal como as sociedades em que ocorrem, não são imutáveis. Doenças, infecciosas ou não surgem, desaparecem ou sofrem modificações conforme o momento histórico. Ainda que não constitua nenhuma novidade, este fato muitas vezes é deixado de lado na busca dos determinantes da ocorrência e distribuição das doenças. Contudo, é o reconhecimento da historicidade das doenças que permite apreender a participação dos fatores não-biológicos. No caso particular da doença de Chagas, desde os primeiros trabalhos que se percebeu a importância de fatores sócioeconômicos na transmissão da doença ${ }^{12}$, mas afora o esta. belecimento da relação simplista POBREZA-MÁS CONDIÇÕES DE VIDA-HABITAÇÃO INADEQUADA-DOENÇA DE CHAGAS ${ }^{23}$ quase nada se avançou no estabelecimento dessa relação. Uma análise superficial da distribuição da doença de Chagas, no Brasil, logo demonstra que a relação acima carece de poder explicativo - a pobreza, as más con-
Recebido para publicação em $24 / 02 / 86$. pique são muito mais encontradiças do que a doença de Cadernos de Saúde Pública, R.J., 2(2):124-140, abr/jun, 1986 
Chagas - assim como as condições ecológicas para a sua transmissão ${ }^{36}{ }^{37}$. Daí que se torna necessário buscar, no processo evolutivo da epidemiologia da doença, os vínculos que esta estabelece com a totalidade, para explicar as transformações que sofre ao longo do tempo.

Neste trabalho, na verdade uma tentativa de extrair a essência de nossa tese de doutoramento ${ }^{36}$, procuramos mostrar como a doença de Chagas, no Estado de São Paulo, se vinculou com a totalidade e sofreu modificações no seu contexto epidemiológico, à medida que o espaço agrário paulista se transformava.

\section{A DOENÇA DE CHAGAS NO ESTADO DE SÃO PAULO: um pequeno retrospecto}

Até por volta de 1970 , quando se interrompe a transmissão natural da doença de Chagas em São Paulo ${ }^{31}$, esta constituiu um considerável problema de saúde pública, afligindo praticamente todos os municípios do Planalto Ocidental Paulista, além de boa parte dos da Depressão Periférica ${ }^{8}$. O principal vetor, de longe o mais importante, era o Triatoma infestans, espécie extremamente bem adaptada ao domicilio humano, capaz de sobreviver em praticamente qualquer ponto do Estado ${ }^{8,36}$. O Triatoma infestans constitui espécie alóctone ao Estado de São Paulo, sendo originária do altiplano andino, de onde foi introduzida via região do Prata ${ }^{1}$. A distribuição do Triatoma infestans no Centro-Sul brasileiro, na década de 1950 , época que parece representar o acme da doença de Chagas em São Paulo ${ }^{36}$, formava um todo homogêneo com centro em São Paulo, atingindo o Norte do Paraná, Sul de Minas Gerais e Sul de Goiás ${ }^{1}$.

Para conhecer como se deu essa distribuição do Triatoma infestans e, por conseguinte, da doença de Chagas, podemos apenas tentar uma recons ${ }^{+}$rução do processo, uma vez que, quando o meio científico se deu conta da sua existência no Estado de São Paulo, o Triatoma infestans já era o principal vetor e a endemia já estava presente em toda a área desbravada do Planalto, isto já em 1914-1916, data dos primeiros levantamentos entomológicos relativos à doença de Chagas realizados em São Paulo ${ }^{6} 16$

Evidentemente, por se tratar de espécie alóctone, de hábitos exclusivamente domiciliares, e por não haver registro algum da presença do Triatoma infestans, ou de qualquer outro triatomíneo no interior de habitações indígenas, seja de São Paulo ou de qualquer outro ponto do país, podemos aceitar que o Triatoma infestans só pode ter sido trazido para São Paulo, a partir da colonização européia, o que nos delimita o período a ser investigado ${ }^{1}$. $\mathrm{Na}$ verdade, não é 
necessário remontar a 1532 para reconstruir o processo de introdução do Triatoma infestans no Estado de São Paulo: o fato parece ter se verificado em período muito mais recente, provavelmente durante o século passado ${ }^{36}$. Devido às suas características, o Triatoma infestans quando infesta uma dada região, dificilmente passa despercebido, uma vez que, graças à sua extrema domiciliação, atinge grandes números, sendo encontrado às centenas num dado domicílio ${ }^{1,35}$. Evidência disso é que, nas áreas em que é encon. trado fora do Brasil, no altiplano andino e na região do Prata, desde o primeiro século de colonização européia, o Triatoma infestans vem sendo mencionado nas crônicas de viajantes, notadamente naturalistas que percorreram a região no século passado ${ }^{20,36}$. O Triatoma infestans encontrou lugar, inclusive no folclore argentino $0^{20}$ e na literatura uruguaia $^{40}$, fatos que não ocorreram no Brasil. Viajantes que percorreram extensamente a então província de São Paulo, não obstante suas descrições minuciosas da flora e da fauna da região, simplesmente não mencionam a presença de triatomíneos domiciliados ${ }^{36}$. Como exemplo, é interessante consultar as crônicas de viagem de Auguste de Saint-Hilaire ${ }^{33,34}$. Alem disso, os investigadores que se preocuparam com a doença de Chagas, no início deste século, mencionam que, a se aceitar o depoimento de naturais das regiōes aonde o Triatoma infestans era encontrado, este havia sido recen. temente introduzido na região ${ }^{6}$.

Ademais, se formos buscar as oportunidades de introdução que o Triatoma infestans teve ao longo da história de São Paulo, veremos que estas se resumem a apenas duas: as incursões dos bandeirantes no século XVII e o comércio de eqüinos e muares que se desenvolveu entre o Centro-Sul brasileiro e as planícies sulinas, nos séculos XVIII e XIX ${ }^{36}$. Estas foram as duas únicas instâncias em que houve um contato terrestre de proporções significativas que permitiria a introdução de um inseto, facilmente transportável, da região do Prata até São Paulo. É interessante notar que a área de distribuição do Triatoma infestans no Centro-Sul Brasileiro é descontínua das áreas de distribuição do Prata e altiplano andino ${ }^{1}$. Parece-nos que a segunda alternativa é mais provável, principalmente levando-se em conta a proporção do comércio existente e o longo tempo que persistiu. Não somos os únicos a sustentar esta opinião ${ }^{1}$.

Ainda que a introdução do Triatoma infestans pareça ser de ocorrência relativamente recente, e que a distribuição deste parece ter respeitado a expansão da fronteira agrícola ${ }^{16,36}$, a doença de Chagas parece ser bem mais antiga na região, existindo antes do avanço da "onda verde" da cafeicultura. Descrições bastante claras do Visconde de Taunay, tanto no romance Inocência como em sua autobiografia ${ }^{41,42}$, 
assim como do missionário Fletcher ${ }^{19}$, mostram que a doença de Chagas existia no sertão paulista, já desde mea. dos do século passado.

Com isso, fica uma idéia da doença de Chagas no Estado de São Paulo: pelo menos desde a segunda década deste século a endemia se distribui pelo planalto Ocidental junta. mente com a fronteira agrícola, sendo o Triatoma infestans o seu principal vetor. Há evidências de que a doença já acometia o homem do sertão paulista antes da chegada da cafeicultura, mas, tudo nos leva a crer, sem a presença do Triatoma infestans, provavelmente sendo transmitida pelo Panstrongylus megistus e Triatoma sordida, espécies freqüentes no Centro-Sul brasileiro 9 .

Como teria se dado a evolução da epidemiologia da doença de Chagas em São Paulo e qual sua vinculação com o pro. cesso de transformação sofrido pelo espaço paulista durante período idêntico, é o que procuramos responder a seguir.

\section{A DOENÇA DE CHAGAS NO ESTADO DE SÃO PAULO: A INADEQUAÇĀO DA CONCEITUAÇÃO CLÁSSICA}

Dentro da conceituação clássica de epidemiologia da doença de Chagas, esta passa a ocorrer a partir do momento em que o homem perturba o equilírio ecológico dos focos silvestres da doença ${ }^{38}$. Com a destruição da floresta e a fuga ou desaparecimento das fontes alimentares dos triatomíneos silvestres (pequenos mamíferos, alguns pássaros), estes passam por um processo de domiciliação, uma adaptação ao novo contexto ecológico. No processo de domiciliação, o homem passa a fazer as vezes de fonte alimentar do triato. míneo, e a circulação do Trypanosoma cruzi passa a se fazer pelo homem, não mais pelos animais ${ }^{2}$. Segundo Pessoa $^{29}$, a doença de Chagas no Estado de São Paulo seria endemia característica das zonas rurais decadentes, de ocupação antiga - uma vez destruída a floresta e empobrecidos seus habitantes, estes são compelidos a construir casas de pau-a. pique, ecótopo ideal do triatomíneo, que passaria a infestar as casas da região, criando condições para a transmissão da doença de Chagas. Estas duas conceituações acima, no caso particular de São Paulo, não se aplicam, por dois motivos:

- o Triatoma infestans, espécie alóctone, não sofreu, em São Paulo, processo de domiciliação ${ }^{35}$.

- além da doença de Chagas ocorrer em regióes recém. desbravadas, próximas à fronteira agrícola ${ }^{7,36}$, não se pode estabelecer uma relação CASA DE PAU.A.PIQUE/DOENÇA DE CHAGAS. A distribuição dessas três categorias é totalmente independente ${ }^{36,37}$. 
Vê-se, portanto, que as conceituações clássicas utilizadas para explicar o processo de distribuição da doença de Chagas não se aplicam ao Estado de São Paulo.

\section{A DOENÇA DE CHAGAS EM SÃO PAULO: UMA EXPLICAÇÃO ALTERNATIVA}

Uma análise da distribuição da endemia chagásica no Estado de São Paulo no decorrer dos anos '50, mostra que esta distribuição se sobrepõe, com uma exceção, à da cafeicultura que se desenvolveu a partir do final do período escravocrata ${ }^{37}$. A exceção mencionada diz respeito à porção sudoeste da Depressão Periférica, aonde, como já mencionamos, teria se verificado a introdução do Triatoma infestans mediante o comércio de eqüinos e muares, cujo centro comercial era Sorocaba ${ }^{30}$.

\section{FIGURA 1}

Distribuição do T. infestans no Sudeste brasileiro na década de 1950 e distribuição da "fazenda escravocrata de café nas então Províncias de Minas Gerais,

São Paulo e Rio de Janeiro, segunda metade do século XIX.

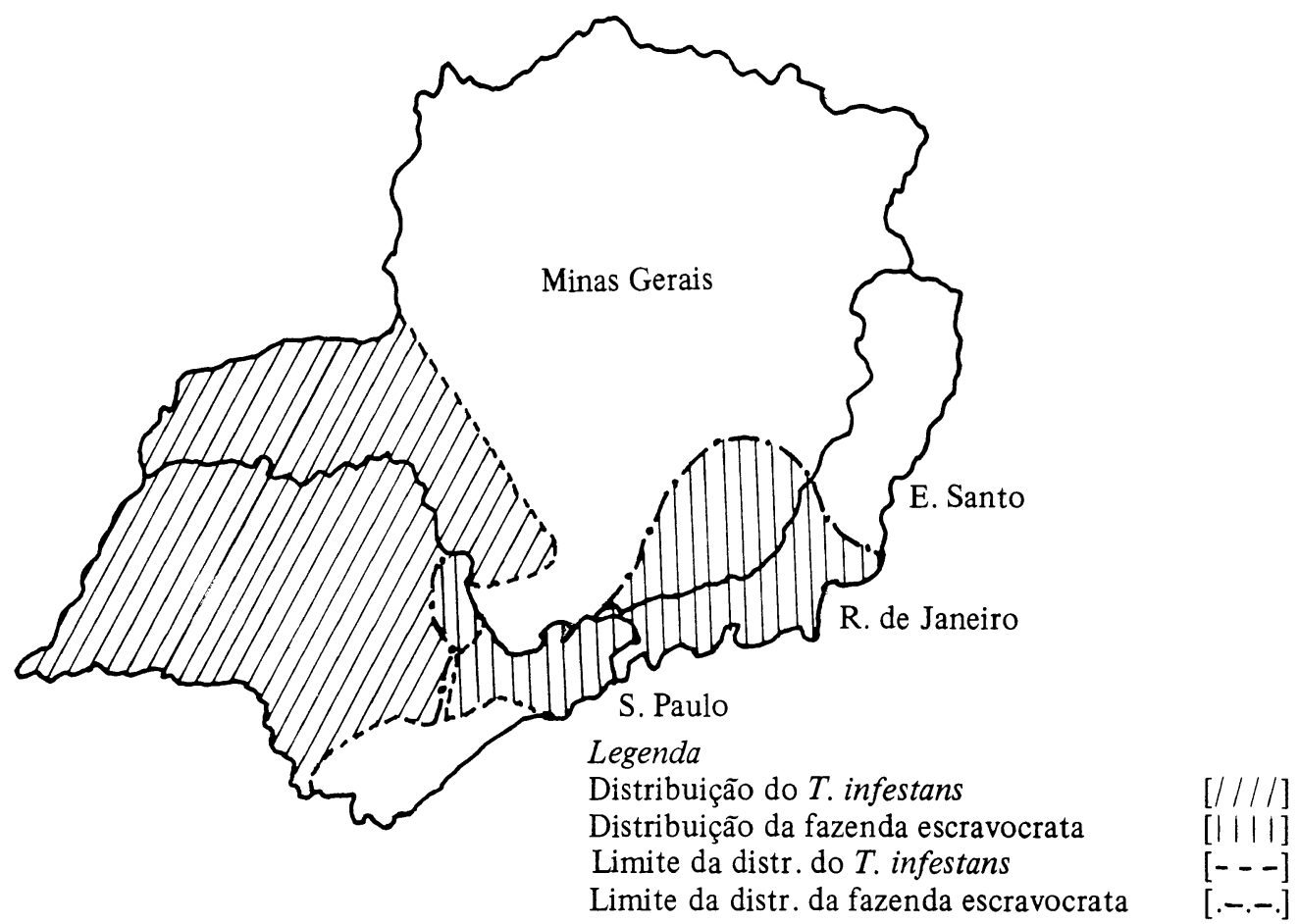

Adaptado de SILVA, L.J. da 8. 
Interessante notar que a distribuição das fazendas escravocratas de café, mineiras e paulistas, do século passado e a distribuição do Triatoma infestans nestes dois Estados são mutuamente exclusivas ${ }^{34,45}$. (Figura 1)

A cafeicultura do final do século XIX em diante se verificou dentro de contexto diferente daquele existente durante o fastio da cafeicultura vale-paraibana ${ }^{5}$. Isto se refletiu na própria organização especial das fazendas dos dois perío$\operatorname{dos}^{26}$. A endemia chagásica transmitida pelo Triatoma infestans parece ter encontrado, no Planalto Ocidental Paulista, excelentes condições para sua disseminação, idéia que se tem quando se analisa os levantamentos epidemiológicos realizados durante a década de $1950^{17}$, aonde se nota que virtualmente todos os municípios eram endêmicos (Figura 2). A estreita vinculação do processo de disseminação da endemia chagásica transmitida pelo Triatoma infestans e o avanço da fronteira agrícola paulista ficam patentes quando notamos que, nos Estados próximos: Paraná, Mato Grosso, Minas Gerais e Goiás estão associados com o modelo agrário paulista no tempo e no espaço:

\section{FIGURA 2}

Distribuição do T. infestans no Estado de São Paulo na década de 1950.

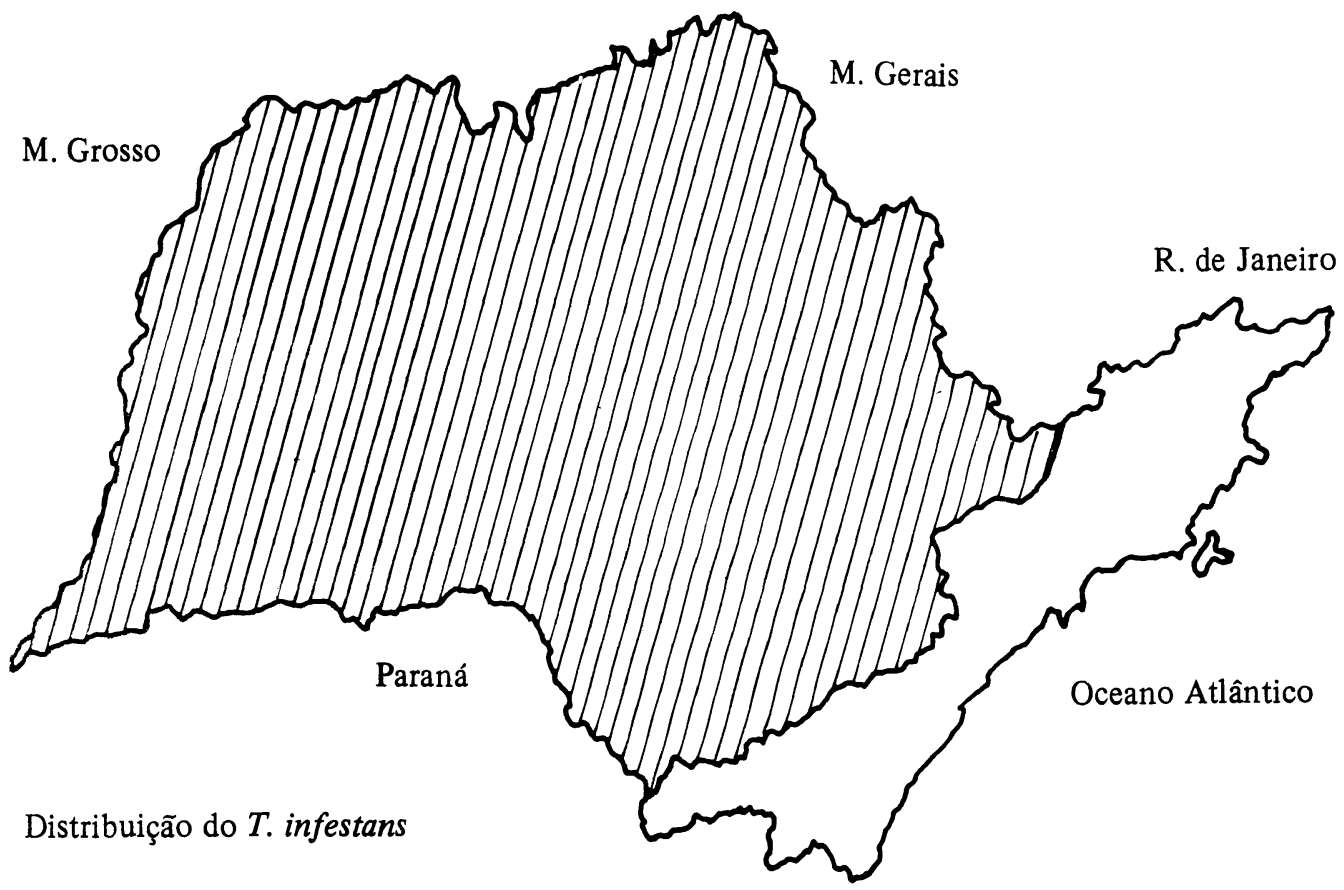

Adaptado de SILVA, L.J. da 36. 
- no Estado do Paraná, a doença de Chagas transmitida pelo Triatoma infestans se limita ao Norte do Estado, por onde avançou a "onda verde", vinda de São Paulo ${ }^{3}$.

- no Estado de Minas Gerais, durante os anos '50, o Triatoma infestans se encontrava apenas nas porções do Sul do Estado e no Triângulo que eram economicamente dependentes de São Paulo ${ }^{3}$.

- no Estado de Mato Grosso, hoje Mato Grosso do Sul, a doença de Chagas transmitida pelo Triatoma infestans tardou a chegar. Durante a década de ' 50 , os únicos vetores assinalados eram o Panstrongylus megistus e o Triatoma sordida ${ }^{3}$, aparentemente autóctones da área (vimos acima que já no século passado, o Visconde de Taunay descrevera a doença na região), só para o final dos anos '60 que o Triatoma infestans é encontrado neste Estado ${ }^{11}$, o que é perfeitamente compreensível, uma vez que o avanço da fronteira agrícola paulista permaneceu estacionário nas barrancas do Rio Paraná durante muitos anos, período em que a pecuária era a atividade econômica predominante da região ${ }^{26}$.

- no Estado de Goiás, a distribuição do Triatoma infestans segue os trilhos da antiga E.F. de Goiás, prolongamento dos trilhos da antiga Companhia Mogiana de Estradas de Ferro, cujos trilhos chegam a Goiás por volta de $1911^{23}$. Durante os anos '50, ainda que a doença de Chagas fosse endêmica em boa parte do território goiano, o Triatoma infestans se limitava à porção do Estado que mais direta. mente se ligava a São Paulo ${ }^{3}$ (Figura 3). Temos então que a distribuição do Triatoma infestans no Centro-Sul brasileiro, durante os anos '50, tinha como centro o Estado de São Paulo, mas essa distribuição não era homogênea, tal como um cŕrculo em crescente expansão. O Triatoma infestans só era encontrado nas áreas com organização espacial similar. Partindo da premissa de que o Triatoma infestans tenha sido introduzido através do comércio de muares e eqüinos que se fazia entre as províncias e Repúblicas sulinas e São Paulo, como vimos anteriormente, a associação desse triatomíneo com a organização espacial que se verificou com a cafeicultura baseada na mão-de-obra assalariada, fica mais evidente quando observamos que, entre o centro de distribuição sulino do Triatoma infestans (Argentina, Uruguai e Rio Grande do Sul $)^{10}$ e São Paulo, este triatomíneo não se estabeleceu ${ }^{10}$, e mesmo em outras áreas do Centro-Sul para onde se destinavam os animais comercializados em Sorocaba; as regiōes auríferas de Minas Gerais e o Vale do Pararba cafeicultor ${ }^{30}$. Vemos que a cafeicultura no Planalto Ocidental Paulista organizou um espaço bastante propício ao Triatoma infestans: uma densidade demográfica mais elevada do que em outras áreas do interior brasileiro, uma maior dispersão na organização dos empreendimentos agri- 
colas e uma grande mobilidade populacional ${ }^{17,26}$, basta ver que o número de imigrantes europeus que se dirigiu às fazendas de café foi cerca de três vezes superior ao que seria necessário, o que evidencia uma grande rotatividade da mão-de-obra agrícola ${ }^{39}$, todos fatores inéditos no sertão brasileiro até a primeira metade deste século, que tornaram - Planalto Ocidental Paulista e as áreas próximas extremamente propícias ao estabelecimento da endemia chagásica transmitida pelo Triatoma infestans.

\section{FIGURA 3}

Distribuição do $T$. infestans no Centro-Sul brasileiro no início da década de 1950.

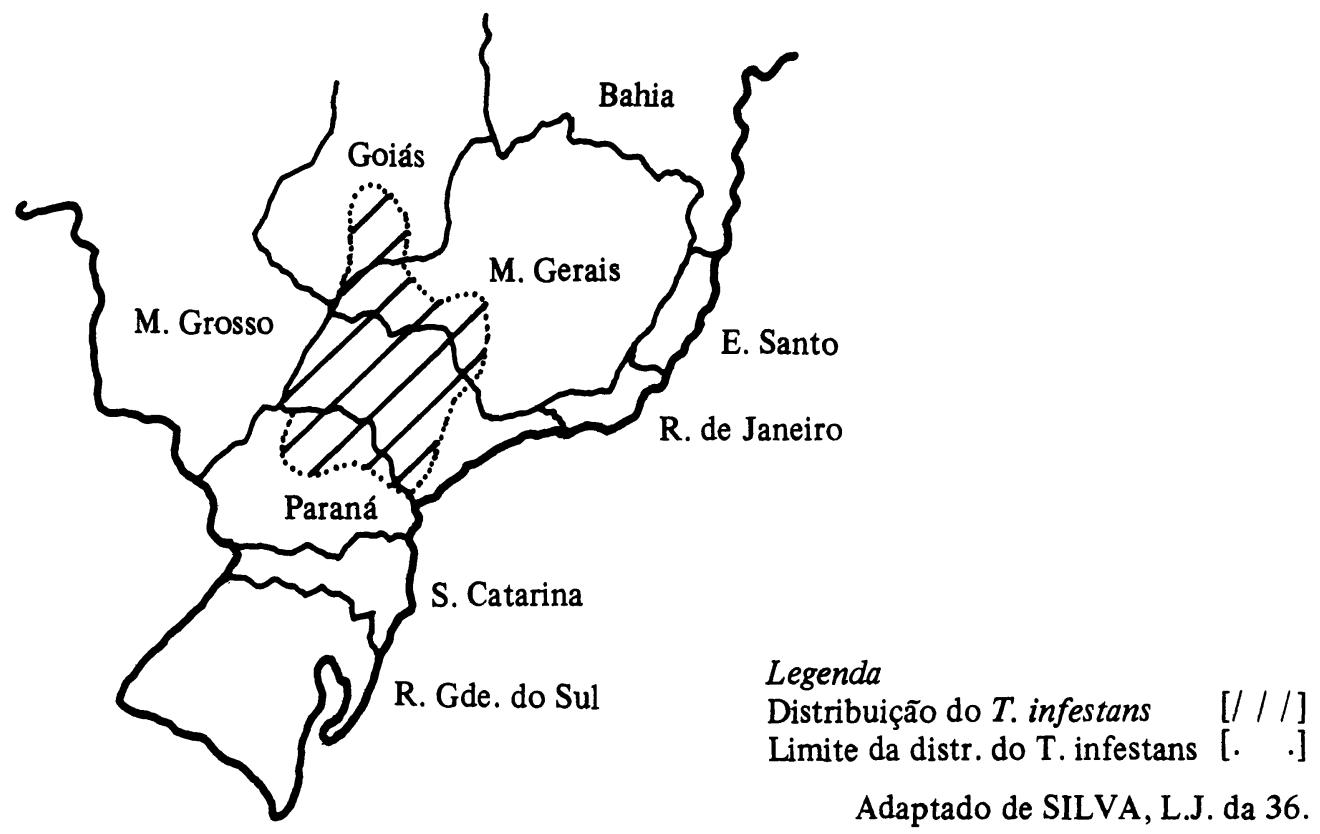

É interessante notar que o Vale do Pararba não é uma região ecologicamente inóspita ao Triatoma infestans, tanto que no início da década de 1950, quando o Vale começa a despertar da decadência provocada pelo declínio da cafeicultura no início do século, a doença de Chagas surge em alguns pontos do Vale. Em Areias e Queluz, do lado paulista, e em Resende e Itaverá, do lado fluminense, são detectados focos de doença de Chagas transmitida pelo Triatoma infes$\operatorname{tans}^{4,45}$. Foi fácil se demonstrar que o foco era realmente recente e não apenas recentemente descoberto, principalmente porque poucos anos antes, extensas investigações tinham sido levadas a cabo na área, mostrando a inexistên. cia da transmissão da doença de Chagas ${ }^{44}$. Os focos foram Cadernos de Saúde Pública, R.J., 2(2):124-140, abr/jun, 1986 
atribuŕdos à migração recente de trabalhadores vindos para a construção da Via Dutra, tendo sido erradicados sem maiores dificuldades. De modo que, se anteriormente não se estabelecera a endemia na região, isso deve ser atriburdo à inadequação do espaço organizado de então em sustentar a transmissão da doença - ainda que o vetor houvesse sido ali introduzido, não teria encontrado condições para a sua disseminação e os poucos focos se extinguiram com o passar do tempo.

A Depressão Periférica paulista, com exceção da porção que se estende de Sorocaba para o Sul, constitui capítulo interessante das relações entre o processo de organização do espaço e a endemia chagásica. Esta porção da Depressão Periférica corresponde, grosseiramente, a uma faixa que compreendida entre Limeira, a Oeste, e Jundiaí, a Leste; avançando, a Norte, pelos contrafortes da Mantiqueira e a Sul até Sorocaba. Esta área não integra a zona endêmica da doença de Chagas, existente até a década de $1950^{\circ}$. No entanto, pelo menos desde os primeiros levantamentos entomológicos, realizados no início do século, sabemos que o Triatoma infestans se encontrava nessa área, porém em pequeno número e não infectado pelo Trypanosoma cruzi $^{6,16}$. É significativo o fato de que esta área, em que a cafeicultura se inicia ainda na primeira metade do século $\mathrm{XIX}^{25}$, portanto em plena fase escravocrata, foi aonde se ensaiaram as primeiras experiências de utilização de mão-de-obra livre na agricultura, no decorrer da década de $1850^{8}$. O desenvolvimento verificado nesta área, depois que a "onda verde" demandava as terras roxas do Planalto, não foi o da decadência econômica, a exemplo do Vale do Parába, ou mesmo de áreas mais recentes do Planalto. Com a queda da produtividade dos cafezais da Depressão Periférica, verificou-se uma evolução para a policultura, com o surgimento e proliferação da pequena propriedade, nascidos do fracionamento das grandes fazendas ${ }^{26,27}$. Este padrão perdura até os dias atuais. Nesta região, não obstante a presença do Triatoma infestans e da proximidade e contiguidade da zona endêmica, jamais se demonstrou a transmissão natural da doença a níveis perceptíveis, a exemplo do que se verificou em alguns munićpios de colonização quase que exclusivamente japonesa, da área então denominada de Nova Alta Paulista: Rinópolis, Bastos, Biriguŕ, nos quais, apesar de constiturrem verdadeiras "ilhas" em meio à zona endêmica da doença de Chagas, não se identificavam com ela ${ }^{36}$, sugerindo uma aparente incompatibilidade da endemia chagásica em São Paulo e a pequena propriedade. Outro aspecto interessante foi a relativa lentidão da ende. mia chagásica em acompanhar o avanço da fronteira agrícola na região da alta Sorocabana, em comparação com a 
proximidade que esta se encontrava da fronteira agrícola por volta de $1916^{16,36}$. Significativo o fato de que o avanço da fronteira agrícola da Alta Sorocabana se deu concomitantemente com a crise do café de ' 29 , a organização do espaço agrário se faz às custas muito mais do algodão e do gado do que do café ${ }^{26}$.

Com o exposto acima, vemos que a doença de Chagas no Estado de São Paulo representa uma forma da endemia que ocorreu graças a um processo especŕfico de organização do espaço geográfico do interior brasileiro. A cafeicultura do Planalto Ocidental Paulista representou uma mudança no modo de produção agrário-brasileira, aproximando-se muito mais do capitalismo industrial dos centros mais desenvolvidos da época ${ }^{5,26}$, que se refletiu numa organização espacial própria, muito propícia à endemia chagásica transmitida pelo Triatoma infestans. Nas áreas em que a organização espacial se afastou do "tipo ideal", a transmissão da doença, ou não, se verificava, como na Depressão Periférica, ou tardava a se verificar, como na Alta Sorocabana e em algumas áreas da Nova Alta Paulista (vide acima) (infelizmente, dados disponíveis acerca da endemia permitem apenas uma semiquantificação da intensidade da transmissão. No presente estudo nos valemos da presença ou ausência do Triatoma infestans e da cronologia de seu aparecimento nas diferentes áreas do Estado).

Existiram dois tipos básicos de padrão epidemiológico da doença de Chagas no Estado de São Paulo: o de trannsmissão pelo Triatoma infestans que, acompanhando o avanço da fronteira agrícola, possivelmente se originou no último quartel do século XIX, e o padrão "sertanejo", cujos vetores eram o Panstrongylus megistus e Triatoma sordida, encontrados no período anterior ao desbravamento do sertão paulista pela cafeicultura. É dentro deste padrão "sertanejo" que tanto o Visconde de Taunay como o missionário Fletcher encontram a doença de Chagas ${ }^{19,41}$. Este padrão foi sendo substituído, à medida que a fronteira agrícola avançava, analogamente à maneira que grileiros e fazendeiros de café deslocavam a agricultura de subsistência que existia no Planalto antes do advento da cafeicultura ${ }^{26}$. Este padrão é semelhante, senão idêntico ao encontrado por Chagas $^{7}$ e mais tarde, por Neiva e Penna ${ }^{28}$, no sertão de Minas Gerais, Bahia e Goiás, na segunda década deste século.

\section{O DESAPARECIMENTO DA ENDEMIA CHAGĀSICA: O ESPAÇO SE TRANSFORMA}

Por volta de 1970 , podia-se afirmar que a transmissão natural da doença de Chagas fora interrompida, ainda que 
a doença não houvesse sido erradicada ${ }^{31}$. Apesar das atividades de combate à endemia terem se iniciado em 1950, o declínio da transmissão só se verifica a partir de $1960^{32}$. Isto se atribui a diversos fatores, um dos quais, sem sombra de dúvida, foi a atividade de combate à endemia desenvol. vida pelo Estado. Esta atividade se intensificou a partir de 1960 , quando a malária deixa de apresentar o problema que fora até então, e os esforços dos serviços sanitários puderam se concentrar na doença de Chagas ${ }^{32}$. Contudo, os próprios responsáveis pelo combate à endemia chagásica reconhecem que uma constelação de fatores sócio-econômicos contribuiu para a interrupção da transmissão da endemia ${ }^{32}$. À primeira vista se é levado a crer que, graças a uma melhoria do padrão de vida no meio rural, a doença entrou em declínio. No entanto, o que se verifica não é bem isto: o maior determinante do declínio da endemia chagásica no Estado de São Paulo teria sido a reestruturação do espaço agrário do Estado de São Paulo.

A partir de 1950 , porém, mais intensamente na década seguinte, verifica-se um significativo êxodo rural, com um decréscimo de $1,3 \times 10^{6}$ habitantes da população rural, e com o desaparecimento de cerca de 270.000 domiculios $^{13,14,18,36}$ (Tabelas I e II). Ao mesmo tempo verifica-se uma modernização da agricultura, com uma maior variedade de culturas, maior consumo de fertilizantes defensivos e maior mecanização ${ }^{12}$.

\section{TABELA 1}

População urbana, rural e total, do Estado de São Paulo, nos anos censitários de 1940,1950, 1960 e 1970, e sua variação decenal

\begin{tabular}{lrrrrrr}
\hline ANO & \multicolumn{7}{c}{ P O P U L A Ç Ã O (nọ habitantes) } \\
& URBANA & \% Var. & RURAL & \% Var. & TOTAL & \% Var. \\
& \multicolumn{1}{c}{ UR VTR } \\
\hline 1940 & 3.168 .111 & & 4.012 .205 & & 7.180 .316 & \\
1950 & 4.804 .211 & 51,6 & 4.330 .212 & 10,0 & 9.134 .423 & 27,2 \\
1960 & 8.149 .979 & 69,6 & 4.824 .720 & 10,3 & 12.974 .699 & 42,0 \\
1970 & 14.432 .244 & 77,1 & 3.526 .449 & $-26,9$ & 17.958 .693 & 38,4
\end{tabular}

Adaptado de SILVA, L. J. da (36).

No mesmo período, o Estado empenha-se ativamente num processo de saneamento da zona rural ${ }^{32}$. E a consolidação da "marcha para o Leste", preconizada anos antes, reaproveitando as terras desgastadas pela cafeicultura de quase um século ${ }^{43}$.

Vemos então que não se trata de uma melhora do padrão 
de vida, mas sim um maciço investimento de capital e trabalho para reabilitar uma economia agrária que, no decorrer das décadas de 1930 e 1940, passa por uma grave crise ${ }^{38}$. Torna-se evidente que a ação sanitária estatal integra um projeto de reabilitação da agricultura paulista, de modo que tanto a ação direta de combate ao vetor da doença de Chagas, como a "melhoria das condições de vida no meio rural" (que na realidade foi a expulsão do trabalhador rural do campo para a cidade, substituŕdo, seja pela máquina, seja pelo trabalhador temporário) são reflexos da transformação que se processou no espaço agrário paulista a partir de 1950 , mais intensamente a partir de 1960.

\section{TABELA 2}

Domicilios existentes na zona rural do Estado de

São Paulo nos anos censitdrios de 1940,1950, $1960 \mathrm{e}$ 1970 e sua variação decenal, absoluta e relativa

\begin{tabular}{llrr}
\hline Ano & No Domicnlios & Var. Absoluta & $\begin{array}{r}\text { Var. Relativa } \\
(\%)\end{array}$ \\
\hline 1940 & 756.060 & & \\
1950 & 824.396 & 68.336 & 9,0 \\
1960 & 927.787 & 103.391 & 12,5 \\
1970 & 657.787 & -270.388 & $-29,1$
\end{tabular}

Adaptado de SILVA, L. J. da (36).

\section{TABELA 3}

Variação relativa da população rural do Estado de São Paulo entre os anos censitários de 1960 e 1970, segundo as microrregiōes

MICRORREGIÃO VARIAÇÃO (\%)

$\begin{array}{lr}\text { Alta Araraquarense de Fernandópolis } & -23,2 \\ \text { Alta Araraquarense de Votuporanga } & -15,9 \\ \text { Divisor Turvo-Grande } & -29,4 \\ \text { Barretos } & -37,5 \\ \text { Alta Mogiana } & -28,1 \\ \text { Planalto de Franca } & -21,7 \\ \text { Alta Noroeste de Araçatuba } & -21,5 \\ \text { Médio São José dos Dourados } & 28,3 \\ \text { Divisor São José dos Dourados-Tietê } & -15,4 \\ \text { São José do Rio Preto } & -29,1 \\ \text { Média Araraquarense } & -27,9 \\ \text { Serra de Jaboticabal } & -25,5\end{array}$




$\begin{array}{lr}\text { Ribeirão Preto } & -32,4 \\ \text { Serra de Batatais } & -25,6 \\ \text { Nova Alta Paulista } & -35,5 \\ \text { Alta Noroeste de Penápolis } & -38,7 \\ \text { Bauru } & -42,5 \\ \text { Araraquara } & -22,5 \\ \text { Depressão Periférica Setentrional } & -8,1 \\ \text { Encosta Ocidental da Mantiqueira Paulista } & -16,0 \\ \text { Alta Paulista } & -37,9 \\ \text { Jaú } & -39,8 \\ \text { Rio Claro } & -23,7 \\ \text { Campinas } & 11,9 \\ \text { Estâncias Hidrominerais paulistas } & -16,1 \\ \text { Alta Sorocabana de Presidente Prudente } & -14,0 \\ \text { Alta Sorocabana de Assis } & -19,3 \\ \text { Ourinhos } & -19,6 \\ \text { Serra Botucatu } & -12,0 \\ \text { Açucareira de Piracicaba } & -13,1 \\ \text { Tatuí } & -19,2 \\ \text { Sorocaba } & -1,2 \\ \text { Jundiaŕ } & -1,9 \\ \text { Bragança Paulista } & -10,9 \\ \text { Vale do Pararba Paulista } & -14,8 \\ \text { Campos de Itapetininga } & 17,2 \\ \text { Paranapiacaba } & 13,0 \\ \text { Grande São Paulo } & -64,9 \\ \text { Alto Paraŕba } & -8,6 \\ \text { Apiaí } & 10,0 \\ \text { Baixada do Ribeira } & 14,1 \\ \text { Baixada Santista } & 3,8 \\ \text { Costa Norte Paulista } & -48,5 \\ & \end{array}$

Adaptado de SILVA, L.J. da (36).

A endemia chagásica que se verificou no decorrer deste século no Estado de São Paulo foi decorrência de uma organização espacial determinada por um modo particular de produção agrária: a cafeicultura baseada na mão-de-obra assalariada. Este contexto epidemiológico particular da endemia chagásica se limitou à distribuição dessa organiza. ção espacial. Quando as condições históricas determinaram a reorganização espacial, a endemia desaparece. Interessante notar que as áreas do Estado em que a transmissão da doença de Chagas pelo Triatoma infestans mais resistiu ao desaparecimento foi na microrregião de Campos do Itapetininga ${ }^{32}$, a única porção da zona endêmica de Chagas no Estado de São Paulo em que a cafeicultura não se desenvolveu. É justamente esta microrregião uma das únicas do Estado a apresentar crescimento positivo da sua população rural no decê- 
nio $1960-1970^{18}$ (Tabela III), e também a apresentar o mais baixo índice de modernização da agricultura de toda a zona da doença de Chagas $^{24}$.

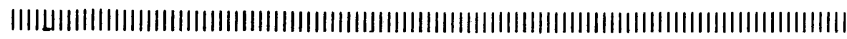

$A$ reconstruction of the emergence, distribution and disappearence of Chagas' disease in the State of São Paulo (Brazil) is undertaken by interpretating existing epidemiological data through historicalmaterialism. Classical concepts concerning the distribution of the disease are shown inadequate to explain the epidemiology of Chagas' disease in São Paulo.

By incorporating an analitical methodology and concepts used in geographical studies, an understanding of the evolution of the disease is achieved. The process is demonstrated peculiar to Central-South Brazil in a particular historical period. Chagas' disease, inasmuch as parasitosis of national expression, must be seen as having distinct epidemiological patterns occuring in differente historical periods.

\section{REFERENCIAS BIBLIOGRÁFICAS}

1. ARAGÃO, M.B. Sobre a dispersão do Triatoma infestans. R. Soc. bras. Med. Trop., 5: 183-91, 1971.

2. BARRETO, M.P. Epidemiologia. In: BRENER, Z. \& ANDRADE, Z. ed. Tripanosoma cruzi e doença de Chagas. Rio de Janeiro, Guanabara Koogan, 1979. p. 89-151.

3. BUSTAMANTE, F.M. Distribuição geográfica dos transmissores da doença de Chagas no Brasil e sua relação com certos fatores climáticos: epidemiologia e profilaxia da enfermidade. R. bras. Malariol. D. trop., 9: 191-210, 1957.

4. BUSTAMANTE, F.M. \& GUSMÃO, J.B. Sobre um foco de Triatoma infestans nos municípios de Resende e Itaverá, Estado do Rio de Janeiro. R. bras. Malariol. D. trop., 5: 23-8, 1953.

5. CARDOSO, F.H. Condições sociais da industrialização: o caso São Paulo. In: —. Mudanças Sociais na América Latina. São Paulo, Difusão Européia do Livro, 1960. p. 186-98.

6. CARINI, A. \& MACIEL, J.J. Distribuição dos Triatomas no Estado de São Paulo. Ann. paul. Med. Cir., 2: 78-9, 1914.; Distribuition des Triatomes dans 1'Etat de São Paulo. Bull. Soc. Pathol. Exot., 7: 229-95, 1914.

7. CHAGAS, C. Descoberta do Trypanozoma cruzi e verificação da Cadernos de Saúde Pública, R.J., 2(2):124-140, abr/jun, 1986 
tripanozomíase americana; retrospecto histórico. Mem. Inst. Oswaldo Cruz, 15: 67-76, 1922.

8. CODA, D.; FALCI, N. \& MENDES, F.A.T. Contribuição para o estudo e a profilaxia da moléstia de Chagas no Estado de São Paulo. R. Inst. Adolfo Lutz, 18: 83-121, 1958.

9. COSTA, E.V. da. Da senzala d colônia. São Paulo, Difusão Européia do Livro, 1966.

10. FORATTINI, O.P. Biogeografia, origem e distribuição de tratomíneos no Brasil. R. Saúde públ., 14: 265-99, 1980.

11. FREITAS, C.A. de. Alguns aspectos da epidemiologia e profilaxia da doença de Chagas. $R$. bras. Malariol. $D$. trop., 26/27: $61-92,1974 / 75$.

12. FUNDAÇÃO INSTITUTO BRASILEIRO DE GEOGRAFIA E ESTATISTICA. Censo agropecuário; São Paulo. In: VIII recenseamento geral 1970. Rio de Janeiro, 1973. v. 3, t. 18 , pt. 1 .

13. FUNDAÇÃO INSTITUTO BRASILEIRO DE GEOGRAFIA E ESTATISTICA. Censo demográfico de 1960; São Paulo. In: __ VII recenseamento geral do Brasil. Série regional. Rio de Janeiro, s. d. v. 1, t. 13.

14. FUNDAÇÃO INSTITUTO BRASILEIRO DE GEOGRAFIA E ESTATISTICA. Censo demográfico; São Paulo. In: VIII recenseamento geral 1970 . Série regional. Rio de Janeiro, 1973. v. 1, t. 28, pt. 1.

15. FUNDAÇÃO INSTITUTO BRASILEIRO DE GEOGRAFIA E ESTATÍSTICA. São Paulo, População. Rio de Janeiro, 1954.

16. GOMES, J.F. Triatomas e moléstias de Chagas no Estado de São Paulo. In: CONGRESSO MÉDICO PAULISTA, 1. São Paulo, 1917. Anais. s.n.t. v. 2 p. 193-214. Col. Trab. Inst. Butantan, 1:401-26, 1918.

17. KELLER, E.C. de S. O habitat rural. In: AZEVEDO, A. de. Brasil: a terra e o homem. São Paulo, Cia. Ed. Nacional, Ed. USP, 1970. v. 2, p. 291-345.

18. KELLER, E.C. de S. População. In: FUNDAÇÃO INSTITUTO BRASILEIRO DE GEOGRAFIA E ESTATISTICA. Geo. grafia do Brasil. Rio de janeiro, 1977. v. 3, p. 143-278.

19. KIDDER, D.P. \& FLETCHER, J.C. $O$ Brasil $e$ os brasileiros. São Paulo, Cia. Ed. Nacional, 1941. v. 2, p. 126-30.

20. LENKO, K. \& PAPAVERO, N. Insetos no folclore. São Paulo, Conselho Estadual de Artes e Ciências Humanas, 1979. cap. 10.

21. LEON, L.A. Contribución a la historia de los transmisores de la enfermedad de Chagas. Medicina, 39: 491-5, 1959.; CONGRESSO INTERNACIONAL DE DOENÇA DE CHAGAS. Rio de Janeiro, 1959. Anais. Rio de Janeiro, Univ. do Brasil, 1962. v. 3, p. 761-70. 
22. MARTINS, A.V. Epidemiologia. In: CANÇADO, J.R. ed. Doença de Chagas. Belo Horizonte, 1968. p. 225-60.

23. MATOS, O.N. de. Café e ferrovias. 2 ed. São Paulo, Alfa-Omega, 1974. (Ser. Sociologia e política).

24. MESQUITA, O.V.; GUSMÃO, R.P. de \& SILVA, S.T. Modernização da agricultura brasileira. $R$. bras. Geog., 39: 3-65, 1977.

25. MILLIET, S. Roteiro do café. In: - Roteiro do café e outros ensaios. São Paulo, Dep. de Cultura, 1939. p. 5-70.

26. MONBEIG, P. Pionniers et planteurs de Søo Paulo. Paris, Armand Colin 1952.

27. MULLER, N.L. Sitios e sitiantes no Estado de São Paulo. Bol. FFCL/USP (132), Ser. Geog., (7): 11-125, 1951.

28. NEIVA, A. \& PENNA, B. Viagem científica pelo norte da Bahia, sudoeste de Pernambuco, sul do Piauí e norte a sul de Goiás. Mem. Inst. Oswaldo Cruz, 8: 73-224, 1916.

29. PESSOA, S.B. Ensaio sobre a distribuição geográfica de algumas endemias parasitárias no Estado de São Paulo. Arq. Hig., 11: 7-25, 1941.

30. PETRONE, M.T.S. $O$ Barão de Iguape: um empresário da época da independência. São Paulo, Cia. Ed. Nacional; Brasılia, MEC/INL, 1976.

31. ROCHA E SILVA, E.O. da.; DIAS JR., J. Suspensão do rociado no combate ao Triatoma infestans em áreas do Estado de São Paulo, Brasil. R. Saúde públ., 3: 173-81, 1969.

32. ROCHA E SILVA, E.O. da; GUARITA, O.F. \& ISHIATA, G.K. Doença de Chagas: atividades de controle dos transmissores no Estado de São Paulo, Brasil. R. bras. Malariol. D. trop., 31: 99-109, 1979.

33. SAINT-HILAIRE, A. de. Segunda viagem do Rio de Janeiro a Minas Gerais e a São Paulo, 1822. Belo Horizonte, Ed. Itatiaia, São Paulo, Ed. USP. 1974.

34. SAINT-HILAIRE, A. de. Viagem à província de São Paulo. Belo Horizonte, Ed. Itatiaia, São Paulo, Ed. USP, 1976.

35. SHERLOCK, I.A. Vetores. In: BRENER, Z \& ANDRADE, Z. ed. Trypanosoma cruzi e doença de Chagas. Rio de Janeiro, Guanabara Koogan, 1979. p. 42-58.

36. SILVA, L.J. da. Evolução do doença de Chagas no Estado de São Paulo. Ribeirão Preto, 1981. [Tese de Doutorado, Faculdade de Medicina de Ribeirão Preto]

37. SILVA, L.J. da. Organização do espaço e doença. Texto de Apoio, Ser. Epidemiel., 1: 159-85, 1985.

38. A SITUAÇÃo econômica da agricultura.' Agricultura, 1 (1): $1-2,1951$.

Cadernos de Saúde Pública, R.J., 2(2):124-140, abr/jun, 1986 
39. SPINDEL, C.R. Homens: escravos, nativos livres e imigrantes. In: - Homens e maquinas na transição de uma econo. mia cafeeira. Rio de Janeiro, Paz e Terra, 1979. p. 54-87.

40. TALICE, R.V.; COSTA, R.S.; RIAL, B. \& OSIMANI, J. Los 100 primeros casos agudos confirmados de enfermedad de Chagas (Trypanosomiasis Americana) en el Uruguay. Montevideo, A. Monteverde, 1940.

41. TAUnAY, A. d'E. Inocência. 7ạ ed. São Paulo, Åtica, 1978. p. 93.

42. TAUNAY, A. d'E. Memorias do Visconde de Taunay. São Paulo, Instituto Progresso Editorial, 1948. p. 395.

43. TESTA, J. A marcha para o leste, na recuperação das terras velhas. Bol. Super. Serv. Cafe, 26: 543-6, 1951.

44. UNTI, O.J. \& MARTINS, H. Inquérito entomológico sobre a moléstia de Chagas no vale do Rio Parahytinga. Nota Preliminar. R. Ass. paul. Med., 18:52, 1941.

45. UNTI, O. \& SILVA, T.L.d. Moléstia de Chagas no Vale do Parába, Estado de São Paulo. Nota sobre a epidemiologia e profilaxia. In: CONGRESSO BRASILEIRO DE HIGIENE, 9. Porto Alegre, 1951. Anais. s.n.t.; arq. Hig. Saúde públ., 6. $131-8,1951$.

46. VALVERDE, O. A fazenda escravocrata de café, no Brasil. R. bras. Geog., 29: 37-81, 1967. 